\title{
PRÁTICA DOCENTE, PESQUISA E INICIAÇÃO CIENTÍFICA: UM OLHAR PARA QUESTÕES AMBIENTAIS NA ESCOLA PÚBLICA
}

\author{
TEACHING PRACTICE, RESEARCH AND SCIENTIFIC \\ INITIATION: A LOOK FOR ENVIRONMENTAL ISSUES IN \\ PUBLIC SCHOOL
}

\author{
Sonia Maria Pereira Lima ${ }^{1}$ \\ Maria Helena Roque Miranda ${ }^{2}$
}

\begin{abstract}
RESUMO
O presente estudo analisa a importância do uso de atividades de pesquisa e iniciação científica no processo de produção do conhecimento do estudante. Com essa pretensão, apresenta-se nesse artigo, o recorte de uma pesquisa desenvolvida por estudantes e professores do Ensino Fundamental e Ensino Médio, a qual procurou identificar de que forma a inexistência da coleta seletiva do lixo afeta a qualidade de vida da população predominante no município de Garanhuns-PE. A amostra do estudo foi constituída por representantes de órgãos municipais, estaduais e ONGs responsáveis pela coleta seletiva no município, além da comunidade estudantil da Escola São José. Utilizamos questionários e, através de estatística descritiva e análise comparativa de conteúdo realiza-se a tabulação dos dados. Conclui-se ressaltando que as práticas educativas ao priorizarem estudos sobre o meio ambiente a partir de atividades desafiadoras que favoreçam e conduzam o estudante a ter atitudes protagonistas materializadas na responsabilidade com a preservação do meio em que vive, contribui para que a escola seja conceituada como espaço de leituras de realidades, de conhecimento produtivo e de relevância social.
\end{abstract}

Palavras-chave: Coleta Seletiva. Educação Ambiental. Desenvolvimento Sustentável.

\footnotetext{
${ }^{1}$ Especialista em Gestão Escolar e Orientação Educacional Professora e Técnica de Ensino da Secretaria de educação do Estado de Pernambuco na Gerência Regional de Educação do Agreste Meridional. Professora Universitária do Curso de Pedagogia pela Plataforma Freire - PARFOR. E-mail: sonia.lima2013@yahoo.com.br

${ }^{2}$ Professora de Biologia do Ensino Médio da Rede Estadual de Ensino do Estado de Pernambuco. E-mail: helenaroquem@ hotmail.com
} 


\section{ABSTRACT}

This study analyzes the importance of using research activities and scientific research in the student's knowledge of the production process. With this claim, it is presented in this article, part of a research developed by students and teachers of high school, which sought to identify how the absence of selective garbage collection affects the predominant population quality of life in the city of Garanhuns -PE. The study sample was made up of representatives of municipal agencies, state and NGOs responsible for selective collection in the municipality, in addition to the student community of St. Joseph School. We used questionnaires and through descriptive statistics and comparative content analysis carried out the tabulation data. The conclusion highlights the educational practices to prioritize studies on the environment from challenging activities that promote and lead the student to have protagonists attitudes materialized in the responsibility for the preservation of the environment they live in, contribute to the school is defined as realities readings space, knowledge production and social relevance.

Keywords: Selective Collection. Environmental Education. Sustainable Development. 


\section{Introdução}

O processo de construção do conhecimento na perspectiva de aprendizagem significativa, a qual privilegia que o "aprender significativamente é ampliar e reconfigurar ideias já existentes na estrutura mental e com isso ser capaz de relacionar e acessar novos conteúdos" (AUSUBEL, 1983), sempre foi alvo de estudos e pesquisas no cenário educacional por ser esse processo uma das maiores necessidades de formação que a escola de educação básica precisa atender na sociedade contemporânea.

A justificativa em relação a essa necessidade, passa dentre outras questões, pelas novas demandas do mercado de trabalho, as quais exigem um perfil de profissional que detenha conhecimentos e competências aliadas à autonomia intelectual, a criticidade, a criatividade, a ética e o bom relacionamento interpessoal em grupo.

Partindo desses parâmetros, um dos objetivos da pesquisa realizada foi adentrar pelas questões de aprendizagem no cotidiano escolar, tomando como referência o Ensino Médio. Nesse sentido, resolve-se trabalhar com os conteúdos de Ciências Humanas e Biologia numa visão transdisciplinar, estimulando a reflexão, o estudo e especialmente a pesquisa sobre questões ambientais no contexto social do Município de Garanhuns-PE. Como eixo norteador, contempla-se o respeito à saúde e a sustentabilidade através do incentivo ao reconhecimento da população aos direitos humanos e a preservação do meio ambiente como forma de contribuir para a melhoria das condições ambientais no Município e para "ampliar os conhecimentos dos estudantes através da formação de novos conceitos de maneira significativa" (AUSUBEL, 1983).

O planejamento desse trabalho embasa-se no Artigo 35- Incisos II e III da LDBEN quando ressalta a necessidade de se vivenciar propostas educativas no Ensino Fundamental e Ensino Médio que contribuam à "preparação básica para o trabalho e a cidadania do educando, para continuar aprendendo, de modo a ser capaz de se adaptar com flexibilidade a novas condições de ocupação ou aperfeiçoamento posteriores", bem como "no aprimoramento do educando como pessoa humana, incluindo a formação ética e o desenvolvimento da autonomia intelectual e do pensamento crítico". 
Dessa reflexão surgiu a necessidade de se elaborar e executar o Projeto DEFENSORES DA NATUREZA NO MUNICÍPIO DE GARANHUNS-PE com o objetivo de desenvolver nos estudantes do Ensino Fundamental e do Ensino Médio, o gosto pelas pesquisas e estudos de iniciação científica, bem como "a cidadania plena para a construção de conhecimentos, o desenvolvimento de valores, atitudes e comportamentos, além da defesa socioambiental e da justiça social" (PNEDH, 2006, p.18).

As inquietações que nos motivaram a realizar esse estudo encontramse, entre outras questões, na comprovação em pesquisas de opiniões e/ou mesmo de campo, de que alguns fatores são considerados essenciais para a destruição do meio ambiente e um deles, é a evidência de que somos nós que contribuímos para esta catástrofe, com nossas atitudes e comportamentos, gerados, sobretudo, pela ausência de uma maior compreensão sobre a importância da coleta seletiva do lixo no meio em que vivemos.

A constatação de que o aumento da temperatura global já se torna realidade tanto no plano local como no plano mundial, além disso, os cientistas calculam um aumento de seis graus centígrados na temperatura terrestre durante esse século. Acrescenta-se a isso a comprovação, segundo dados levantados na Prefeitura Municipal de Garanhuns através da Secretaria de Serviços Públicos e Obras, de que são coletadas diariamente 120 toneladas de lixo e por mês são reciclados apenas 6 a 8 toneladas. Além disso, ainda é reduzido o número de famílias que realizam coleta seletiva no município, sendo informado por essa secretaria na ocasião da pesquisa, que menos de $50 \%$ da população de Garanhuns realiza coleta seletiva, sendo necessário intensificar esse serviço no município.

É fato também que em estudos realizados na escola no ano de 2008 , durante as aulas de Biologia e Ciências Humanas, foi possível perceber no conjunto dos depoimentos dos estudantes, que suas famílias além de não realizarem a coleta seletiva de rejeitos, não eram assistidas pelos órgãos públicos com essa coleta e, com cuidados básicos de higiene e saúde em relação ao tratamento do lixo e meio ambiente, ao qual têm direito conforme expresso no Plano Nacional da Educação dos Direitos Humanos (PNEDH, 2006). Muitas vezes devido à ausência de informações sobre o assunto e/ou conhecimento sobre os 
serviços disponibilizados pela Prefeitura para a realização da coleta seletiva.

Diante dessa constatação, percebeu-se a importância de estimular mudanças nas atitudes dos estudantes e dessas famílias em relação ao tratamento e coleta seletiva do lixo, com o intuito de se disseminar a cultura da preservação ambiental no Município. Nesse caso, através de pesquisas bibliográficas e de campo, estudos e discussões acerca da situação dos rejeitos industriais e em saúde e, seus impactos ambientais no Município, bem como de entrevistas semiestruturadas, procurou-se conhecer a visão da população do município e da comunidade escolar sobre o assunto em pauta.

Um dos fatores que motivou o interesse de estudantes e professores por essa pesquisa centrou-se principalmente na necessidade de informar a população do entorno da escola e da comunidade escolar sobre a importância da coleta seletiva, da reciclagem do lixo e dos danos que o lixo provoca à saúde e ao meio ambiente, uma vez que:

Precisamos ter consciência da importância da coleta seletiva, como também da conscientização da população acerca da mesma. Por isso faz necessário trabalharmos nas escolas, educando e conscientizando os nossos alunos para desenvolvermos um trabalho de preservação do meio ambiente (PCN, 1996, p. 76).

Partiu-se do pressuposto de que a escola ao inserir no currículo escolar, o estudo acerca de questões socioambientais com ênfase na iniciação científica, há ricas possibilidades de contribuir significativamente para aguçar o espírito crítico e criativo do estudante, bem como para a formação de agentes transformadores do meio em que vivem. Acrescenta-se a isso que, pesquisar e estudar sobre a importância da coleta seletiva e o bem que promove à saúde da população pode ser considerado hoje, um dos principais caminhos para a preservação ambiental.

É fato que, os estudantes participando desse processo de construção de conhecimentos aguçam a criatividade e o senso crítico, bem como aprendem a questionar e a posicionar-se com criticidade frente às questões sociais existentes no meio em que vivem. Além disso, ao ser incentivado este tipo de atividade de pesquisa no cotidiano escolar, se impulsiona o estudante a ter atitudes protagonistas em relação ao meio 
ambiente, uma vez que a partir da pesquisa e da tentativa de analisar de que forma a inexistência da coleta seletiva de rejeitos no município afeta a qualidade de vida da população, estes estudantes estarão contribuindo tanto para a melhoria das condições de vida ambientais no município, como para instruir a população a realizar a coleta seletiva.

Assim, partindo do entendimento de que através desse tipo de prática educativa, há ricas possibilidades da população de Garanhuns entrevistada, compreender os cuidados necessários para com o meio ambiente e mudar hábitos ambientais, realizou-se uma pesquisa de campo na Escola Estadual São José localizada à Av. Rui Barbosa, 715, Heliópolis no município de Garanhuns - PE, envolvendo estudantes de vinte e duas (22) turmas do Ensino Fundamental e duas (02) do Ensino Médio. O município de Garanhuns, no Agreste de Pernambuco, sendo delimitado pelos paralelos $8^{\circ} 48^{`} 0^{\prime} / 8^{\circ} 58^{`} 0^{\prime \prime} \mathrm{S}$ e pelos meridianos $36^{\circ} 10^{`} 0^{`} / 36^{\circ} 50^{`} 0^{\prime} \mathrm{W}$ (Figura 1) e por vinte e dois (22) municípios circunvizinhos (Figura 2).

FIGURA 1 - Mapa de Localização do município de Garanhuns-PE

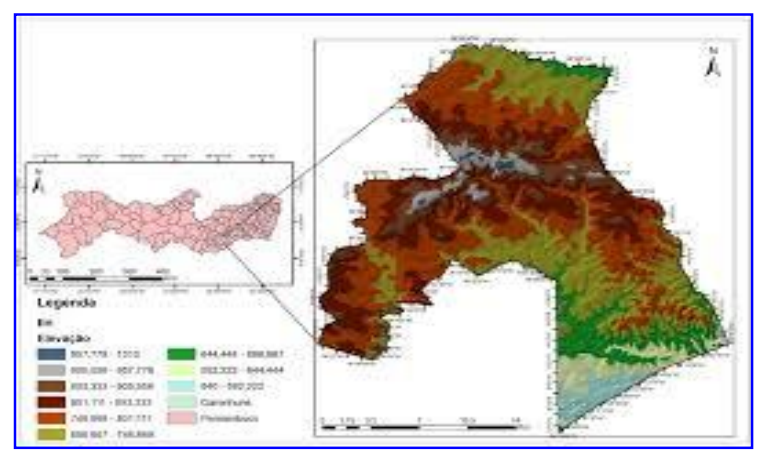

FIGURA 2 - Mapa de localização dos municípios circunvizinhos Garanhuns-PE

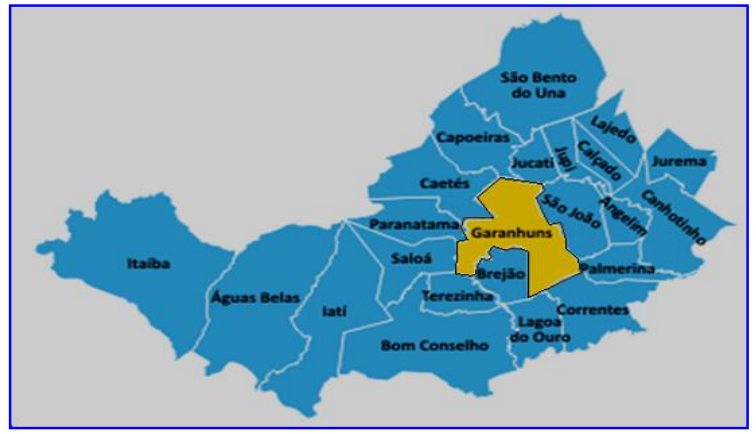


Os procedimentos da pesquisa foram: aplicação de questionários com perguntas abertas e fechadas dirigidas aos alunos das vinte e quatro turmas objeto de estudo nessa pesquisa sobre a realização da coleta seletiva do lixo no bairro onde moram, bem como realização de entrevistas com representantes dos órgãos públicos responsáveis direta ou indiretamente pela coleta seletiva do lixo no Município. Os indicadores de resultados foram assim distribuídos: pesquisa bibliográfica sobre a importância da coleta seletiva de rejeitos industriais e em saúde à qualidade de vida da população, bem como as consequências de sua inexistência para a sobrevivência do meio ambiente.

Estudos em grupos para compreensão, interpretação, análise e pesquisas em grupo, visando o desenvolvimento da parte teórica e para a pesquisa de campo, entrevistas com representantes das diversas instâncias sociais envolvidas direta ou indiretamente com a limpeza e a saúde pública no Município; desenvolvimento de entrevistas formais e conversas informais com estudantes do Ensino Fundamental e Ensino Médio; visitas as instituições responsáveis pela coleta de rejeitos industriais e em saúde no Município e ao aterro sanitário; análise, interpretação e elaboração de gráficos estatísticos para apresentação dos dados colhidos na pesquisa de campo realizada; organização do texto final.

\section{Análise e discussão dos resultados}

Observando os resultados da pesquisa de campo realizada com os estudantes das turmas do Ensino Fundamental e Ensino Médio da Escola Estadual São José, verificam-se em seus depoimentos as precárias condições de higiene e saúde oferecidas em suas residências no que se refere à coleta seletiva de rejeitos.

Nesse sentido, um dos aspectos que merece destaque refere-se à constatação do conhecimento limitado que possuem sobre essa coleta e a necessidade de realiza-la em sua residência. Nesse caso, se percebe

que muitas famílias desconhecem seu significado e a existência desse tipo de serviço público no Município. 
Por outro lado, constata-se que os serviços públicos da coleta de rejeitos no município não tem sido uma prática que envolve todos os bairros do município. Primeiro por falta de informação da população acerca desse tipo de coleta e, segundo, devido à ausência de um trabalho de sensibilização e conscientização da população sobre a importância da preservação ambiental pelos setores responsáveis por esse tipo de serviço público no município, bem como de divulgação junto a família desses estudantes, dos horários e manuais com o passo a passo de como fazer uma coleta seletiva de rejeitos.

Dessa forma, apenas $15 \%$ das famílias dos estudantes do ensino fundamental e $13 \%$ do ensino médio entrevistadas têm realizado esse tipo de coleta, conforme gráfico 1 abaixo relacionado

GRÁFICO 1 - Pesquisa com as famílias dos estudantes sobre coleta seletiva

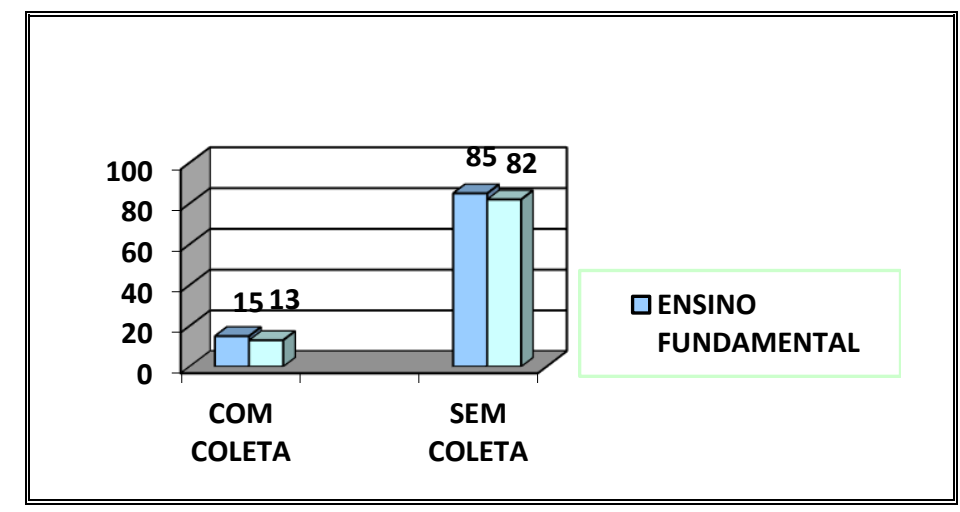

Fonte: Trabalho de campo via áudio realizado pelas autoras em 2007.

Para conhecer melhor essa realidade, foi realizada uma visita a Secretaria de Obras do Município e na ocasião entrevistou-se o Secretário de Obras Sr. Jones Rodrigues Sena Filho, o qual repassou informações precisas sobre os serviços de educação ambiental em atuação no Município e, gentilmente cedeu um transporte para que a fosse realizada uma visita aos locais de coleta de rejeitos.

Nesse caso, foi possível visitar a LOCAR, empresa de caráter privado que atende a toda região urbana e rural, sob a supervisão da Prefeitura, a qual é responsável no município pela gestão de resíduos e limpeza, 
sendo também encarregada pela coleta de rejeitos orgânicos e, por disponibilizar um carro de apoio para a coleta seletiva.

Em leituras no regimento interno de funcionamento da LOCAR, observou-se que uma de suas finalidades é assegurar a limpeza e coleta seletiva de rejeitos orgânicos no município. Cabe aqui lembrar que, em entrevista a um dos funcionários encarregado de fazer a coleta nos bairros da cidade, tomou-se conhecimento de que a coleta é realizada semanalmente e para não deixar de atender a nenhuma rua ou bairro é organizado um cronograma com horário e nomes das ruas contempladas a cada semana. Ressaltou também que em muitas ruas, as famílias nunca se preocuparam em recolher os rejeitos separados em orgânico e inorgânico, pois além de misturados muitas vezes os colocam expostos em frente às residências sem noção de higienização para ser recolhido pela LOCAR.

Em visita realizada ao Aterro Sanitário, localizado na BR- 42, nas proximidades do Município de Miracica distrito de Garanhuns-PE, o funcionário da Prefeitura de Garanhuns responsável pelo Aterro Sanitário, nos explicou que todos os dias chegam em média de 120 a 150 toneladas de lixo, o qual é pesado e segue para a célula, onde recebe a cada 5 metros de rejeitos uma cobertura de 40 centímetros de barro. Dentre todas as explicações ressalta-se que o Aterro Sanitário é composto de três células, a primeira com quatro camadas, a segunda e a terceira com três camadas. Segundo Vilhena e Politi:

\footnotetext{
Aterro sanitário são resíduos sólidos urbanos no solo, sem causar danos ou riscos à saúde pública e a segurança, minimizando os impactos ambientais. Método este que utiliza os princípios da engenharia para confinar os resíduos sólidos ao menor volume permissível, cobrindo-os com uma camada de terra na conclusão de cada jornada de trabalho ou em intervalos menores se for necessário (VILHENA; POLITI, 2000, p. 84).
}

Ao chegarmos à Associação dos Catadores da Coleta Seletiva ASNOV (Associação Nova Vida), a qual funciona em um galpão cedido pela Prefeitura Municipal de Garanhuns e dispõe de um único carro, cedido pela LOCAR para a coleta da cidade. Na ASNOV em 2010 havia 65 catadores, mas 2015 o grupo é de apenas 17 pessoas, sendo 11 coletores espalhados pela cidade e sete que trabalham no galpão realizando a separação do material. 
Mediante as respostas obtidas nas entrevistas, percebemos que a coleta do lixo orgânico não ocorre em todas as ruas no Município de Garanhuns-PE, por serem essas ruas de difícil acesso. No entanto, a Constituição diz que todo cidadão tem direito a um ambiente de qualidade e isso está deixando de acontecer, sobretudo nos bairros mais carentes sendo necessário se estudar alternativas que modifiquem essa situação.

Além disso, essa ausência da coleta obriga alguns moradores a realizarem a queima de lixo, alterando o meio ambiente e contribuindo para a devastação da camada de Ozônio do nosso planeta, em função dos gases emitidos. No aterro sanitário percebemos alguns aspectos que não consideramos como uma operação segura, pois encontramos diversos resíduos sólidos antigos, descompactados, quando estes deveriam ser cobertos todos os dias. Encontramos resíduos a céu aberto e em contato com animais (pássaros), sujeitos a chuva e a liberação de gases com odor, o que pode causar riscos para a saúde pública.

Diante disso, ao se analisar a situação ambiental do Município de Garanhuns- PE constatou-se que há necessidade de se preservar o meio ambiente, verificando as condições do aterro sanitário e conscientizando à população sobre os cuidados que precisam ter em relação a esse ambiente, a fim de viabilizar um modo de vida mais equilibrado, harmônico e sustentável. Com essa pesquisa foi possível também perceber a importância de intervir junto à comunidade, através da realização de seminários que possam instruí-los sobre o assunto, promover oficinas que atribuam tratamento preferencial à reciclagem para minimizar os níveis de poluição ambiental e desperdício dos recursos naturais no município e, especialmente transformando a escola num núcleo interdisciplinar de apoio dessa conscientização em parceria com estudantes de Universidades e escolas do Município.

Nos resultados da pesquisa realizada, constatou-se que um percentual de aproximadamente $64 \%$ da população do entorno da escola e da comunidade escolar desconhece a existência da coleta seletiva no município e, também de que no município existe um órgão responsável por oferecer esses serviços à população de Garanhuns. Além disso, também se evidencia que mais de $80 \%$ da população entrevistada afirmaram nunca ter participado de encontros onde a Secretaria de Saúde ou profissionais da Prefeitura tenham apresentado informações 
acerca da importância de se realizar a coleta seletiva de rejeitos e resíduos e, muito menos, que exista um posto de coleta seletiva no município. De acordo com o gráfico 2 abaixo, confirmamos esses resultados.

GRÁFICO 2- Pesquisa com a população do entorno da escola e comunidade escolar

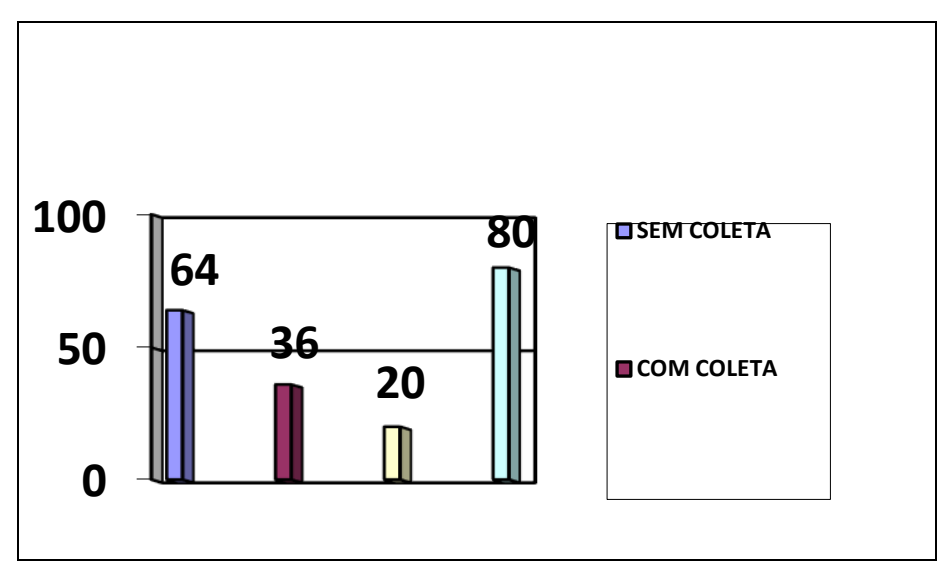

Fonte: Trabalho de campo realizado pelas autoras em 2007.

De acordo com o gráfico acima, apenas 36\% das famílias entrevistadas fazem ou conhecem o processo de coleta seletiva no município, e as análises confirmam que mais de $80 \%$ dessas famílias desconhecem a existência dessa coleta em seu bairro ou município.

Sabemos que o acúmulo de lixo em casa, nas ruas e/ou nos mais variados espaços tem contribuído para uma série de problemas ambientais e até de saúde à população, uma vez que as consequências da disposição inadequada do lixo no meio ambiente são a proliferação de vetores de doenças, a contaminação de lençóis subterrâneos e do solo pelo chorume (líquido escuro, altamente tóxico, formado na decomposição dos resíduos orgânicos do lixo) e a poluição do ar, causada pela fumaça proveniente da queima espontânea do lixo exposto.

Nesse sentido, a coleta seletiva de rejeitos aparece não como a solução final, mas como uma das possibilidades de redução do problema, pois nosso lixo é constituído por diversos tipos de material, grande parte reaproveitável e, portanto, a coleta seletiva aparece como uma 
possibilidade de minimização do problema, visto que consiste na separação de tudo o que pode ser reaproveitado, enviando-se esse material para reciclagem.

Há na visão da população entrevistada necessidade de que a coleta seletiva seja realizada em todas as residências a fim de que possam contribuir para a melhoria ambiental e a mudança de atitude da própria população entrevistada, a qual muitas vezes contribui para a poluição ambiental. E, diante dessa realidade, as pesquisas afirmam que se faz necessário informar e sensibilizar a população sobre a importância da coleta seletiva de rejeitos e da preservação ambiental começando dentro de sua própria casa, a fim de que haja novas atitudes e posturas com relação ao meio ambiente.

Diante disso, a escola implementando ações que coloquem a questão ambiental como foco de mudanças de atitudes para com o meio ambiente e a melhoria social de sua comunidade escolar, oportuniza o fortalecimento de práticas individuais e sociais entre os estudantes e, além disso, prepara esses estudantes para a vida em sociedade, assegurando-lhes a construção significativa do conhecimento e a vivência de valores que promova o exercício pleno de sua cidadania à luz da preservação do meio ambiente.

A prática de educação ambiental na escola de educação básica, compromete-se, de um lado, com o sujeito ativo, com a pessoa humana que se apropriará dos conhecimentos socioambientais para se aprimorar, como tal no mundo do trabalho e na prática social contribuindo com a preservação do meio ambiente a partir da realização de pesquisas que sensibilizem a comunidade a ter amor ao meio em que vivem e, de outro, com uma aprendizagem permanente, considerando como elemento central dessa formação a construção da cidadania em função dos processos sociais que se modificam.

Cabe aqui lembrar que, o estudo das questões ambientais na escola de Educação Básica não pode se resumir a uma simples comemoração no dia dedicado ao meio ambiente, ou mesmo a uma série de atividades nas aulas de Ciências, Biologia e Geografia, mas deve ser encarada como uma prática educativa que contribui de forma significativa para o exercício da cidadania do ser humano na sociedade contemporânea. Assim, de acordo com Krasilchik: 
A atividade esporádica de cuidados ambientais, não é a solução "mágica" para os problemas ambientais, pois estas soluções ocorrem a partir de hábitos contínuos em prol do meio ambiente, uma vez que (...) é um processo contínuo de aprendizagem de conhecimento e exercício de cidadania, capacitando o indivíduo para uma visão crítica da realidade e uma atuação consciente no espaço social KRASILCHICK (1986, p. 1959).

Após a realização da pesquisa de campo e bibliográfica, foram analisados os dados e os resultados apontaram que a maior necessidade da comunidade entrevistada era ter um contato direto com as informações sobre a coleta seletiva no bairro em que residem a fim de contribuir com a saúde ambiental. Para tanto, os entrevistados apontaram como caminho para efetivar essa contribuição com o meio ambiente, a realização de encontros com a comunidade escolar para orientá-los quanto à seletividade do lixo desde a sua própria casa.

Nesse caso, elaboramos um plano de ação para que os estudantes envolvidos na pesquisa estudassem os resultados e através de fundamentações teóricas pudessem informar a comunidade escolar sobre a importância da coleta seletiva e preservação ambiental.

Outra situação pedagógica discutida e pensada no momento de estudos teóricos entre professores e estudantes foi implantar na escola um posto de coleta seletiva para que os estudantes da escola, desde a $5^{\text {a }}$ série do ensino fundamental realizassem em suas residências a coleta seletiva e levassem para o posto fixado na escola. De posse dessa coleta seletiva a escola convida alguém da Prefeitura municipal para recolher a coleta seletiva semanalmente na escola.

\section{Impactos}

Essa prática educativa de incentivo a educação ambiental, foi muito satisfatória e produtiva na escola, pois os estudantes que em sua maioria eram bastante introspectos e sem interesse nas aulas, passaram a ter prazer de participar das rodas de discussões e desenvolveram o hábito de leitura, o que representou um avanço na aprendizagem, pois, mais de $50 \%$ dos estudantes, sobretudo do Ensino Médio não 
gostavam de ler, o que dificultava seu rendimento nas disciplinas de Ciências Humanas e Língua Portuguesa.

Além disso, essa prática educativa permitiu que os estudantes não se deixassem enganar pelas aparências, dado ao fato de construírem o conhecimento a nível consciente, num contexto de diálogos abertos, críticos e reflexivos, em que já não cabia memorizar conhecimentos com o intuito de fazer uma prova no final de cada unidade didática. Nesse sentido, essa prática educativa oportunizou os estudantes a desenvolverem a capacidade de continuar aprendendo, uma vez que sua maior finalidade foi estimulá-los a participar ativamente de atividades desafiadoras voltadas à reflexão, a "pensar cientificamente através da pesquisa e da problematização" (PIAGET, 1983, p.90) e agir com competências na e para a dinâmica do processo de ensino e de aprendizagem.

Outro impacto positivo alcançado com a realização da atividade na escola resume-se a melhoria da aprendizagem dos estudantes em leitura e produção escrita, bem como o interesse dos estudantes com a prática da pesquisa e as atividades de iniciação científica. Esse fato revelou, durante e após a realização da atividade que o processo de produção do conhecimento passa a ter mais sentido e significado para os estudantes.

Acrescenta-se a isso que na medida em que foi constatado que ainda há pouco conhecimento da população sobre o serviço de coleta seletiva de rejeitos que vem sendo ofertados no município, os estudantes junto aos professores mobilizaram a equipe gestora da escola (Gestora, Secretária, educadora de apoio) a adquirirem alguns containers para coleta seletiva na escola, cujo objetivo era instruir os estudantes a preservação ambiental desde a escola e a ter um melhor entendimento acerca da coleta seletiva à saúde pública e ambiental.

A partir do incentivo dessa prática na escola, dos estudos e conteúdos pesquisados nos livros e dos resultados da pesquisa de campo, os estudantes passaram a compreender que a leitura deve fazer parte de toda sua vida, e que na escola, essa prática pode ser considerada o passaporte para o exercício da cidadania de todo individuo, uma vez que permite a compreensão e a descoberta de novos conhecimentos, além de oportuniza-los a ter autonomia intelectual e a sua atuação 
enquanto sujeito histórico capaz de intervir em seu cotidiano e modifica-lo.

Nas rodas de discussões após a realização da pesquisa, perceberam-se os comentários dos estudantes e o amadurecimento que passaram a ter acerca da preservação do meio ambiente e da situação de coleta seletiva existente no município onde vivem. Nesse sentido, começam a surgir alguns questionamentos e novos entendimentos dos estudantes sobre a coleta seletiva e os benefícios da reciclagem. Para muitos estudantes foi possível perceber que a questão da reciclagem do lixo realmente muito importante para a saúde do nosso planeta, pois ajuda no controle do Efeito Estufa e além de ser uma atitude inteligente também representa uma fonte de renda.

Para os docentes e a educadora de apoio da escola, essa experiência confirma a concepção de que o trabalho em equipe dá certo, quando se tem, dentre outros elementos (conteúdo, prática docente, metodologia, ensino, apoio da gestão escolar) e Sobretudo, um planejamento que prioriza o uso das ferramentas de pesquisa e de iniciação científica (experimentação, observação, pesquisas bibliográficas e de campo) no trabalho com os conteúdos escolares, há ricas possibilidades de se conduzir o estudante a adquirir uma aprendizagem significativa no momento da produção do conhecimento.

\section{Considerações finais}

Conclui-se, portanto, com o levantamento dos dados e os estudos teóricos realizados neste trabalho de pesquisa que, a efetivação de práticas educativas que priorizam o meio ambiente e a atuação do estudante na melhoria desse ambiente a partir de atitudes e comportamentos que o despertem para o protagonismo juvenil e a responsabilidade com o meio em que vivem a escola passa a ser conceituada como espaço de leituras de realidades, de conhecimento produtivo e de relevância social. Como afirma Delors:

A Educação Ambiental tem que ser feita desde cedo, em casa, não só a partir da escola para daí em diante começar a formar cidadãos preocupados com o meio ambiente em que eles vivem, e tentar deste modo minimizar no presente e no futuro os impactos causados pela nossa espécie não agredindo mais nosso 
planeta e buscando uma interação harmoniosa entre o homem e a natureza (DELORS, 2001, p. 288).

Os estudantes sendo estimulados a realizar esse tipo de atividade em seu processo de formação, são oportunizados a atuar como os sujeitos de seu processo de aprendizagem e a construir significados para o que aprendem, por meio de múltiplas e complexas interações com os objetos de conhecimento. E nesse sentido, o professor passa a ser mediador de sua formação contribuindo para a aquisição de novos saberes pelos estudantes.

Além disso, os resultados apontaram que as atividades de pesquisa realizadas fortaleceram a identidade, a autoestima e o sentido de coletividade dos estudantes, e portanto, contribuiu para que estudantes e professores sensibilizassem a comunidade a buscar e construir respostas para o seu cotidiano ambiental de forma bastante coerente e significativa.

Para tanto, os eixos de aprendizagem desenvolvidos foram à produção e socialização de conhecimentos, tomando como referência de ensino a metodologia da problematização e da pergunta, uma vez que os estudantes são oportunizados a problematizar o senso comum sendo inserido no contexto de produtor de conhecimentos advindo de um diálogo estabelecido entre os diversos campos do saber, priorizando as questões sociais vigentes no entorno da escola, sob o olhar dos seus próprios protagonistas.

Ressalta-se também que essa prática ambiental vem contibuindo para elevar a autoestima de estudantes, professores e comunidade escolar, os quais vêm expressando nos espaços de discussão e interlocução que se sentem gratificados pelo legado que vêm adquirindo à luz dessas pesquisas e das contribuições registradas através de acervos fotográficos e relatórios dos docentes, equipe gestora e comunidade escolar em portfólio, bem como a dos estudantes no Diário de Bordo todas as vezes em que atuam como protagonistas da experiência de socializar atividades com outros estudantes e a comunidade, fazendonos crer nas palavras sábias de nosso eterno Paulo Freire "A mudança é possível.... e todo futuro é uma criação do presente"(FREIRE,1997, p.30), mas se faz necessário que a escola seja vista como espaço de interlocução, construção de saberes e desconstrução de políticas educacionais que assumem esteriótipos capazes de negar a sociedade o 
verdadeiro papel e função social da escola " formar cidadãos críticos e produtores de cultura e conhecimentos. $\mathrm{O}$ estudante aprende quando o professor aprende e, ambos aprendem quando pesquisam. Nesse caso, como postula Freire:

Não há ensino sem pesquisa e pesquisa sem ensino. Esses quefazeres se encontram um no corpo do outro. Enquanto ensino, continuo buscando, reprocurando. Ensino porque busco, porque indaguei, porque indago e me indago. Pesquiso para constatar, constatando, intervenho intervindo educo e me educo. Pesquiso para conhecer o que ainda não conheço e comunicar ou anunciar a novidade (FREIRE, 1997, p.32).

Assim, os estudantes sendo estimulados a realizar esse tipo de atividade em seu processo de formação, são oportunizados a atuarem como sujeitos de seu processo de aprendizagem e a construírem significados para o que aprendem, por meio de múltiplas e complexas interações com os objetos de conhecimento. E nesse sentido, o professor passa a ser mediador de sua formação contribuindo para a aquisição de novos saberes pelos estudantes.

Sob esse enfoque, percebe-se que são muitas as contribuições que estudos sobre a preservação ambiental e a coleta seletiva de rejeitos podem oferecer à melhoria do meio ambiente e da saúde pública não só no município de Garanhuns, mas de todas as sociedades. E com uso das ferramentas de pesquisa e iniciação científica, além dos estudantes serem desafiados a novos contextos de aprendizagem, têm a oportunidade de fortalecer o protagonismo e ter uma postura científica desde o Ensino Fundamental. No entanto, há necessidade de atualização da prática docente para planejar e desenvolver atividades inovadoras na perspectiva da educação ambiental com uso da pesquisa e iniciação científica, a fim de que possam contribuir para a preservação ambiental, tendo estas ferramentas pedagógicas como aliadas em sua atuação profissional.

Conclui-se ressaltando que as práticas educativas ao priorizarem estudos sobre o meio ambiente a partir de atividades desafiadoras que favoreçam e conduzam o estudante a ter atitudes protagonistas materializadas na responsabilidade com a preservação do meio em que vive, contribui para que a escola seja conceituada como espaço de leituras de realidades, de conhecimento produtivo e de relevância social. 


\section{Referências}

AUSUBEL, D. P.; NOVAK, J. D., HANESIAN, H. Psicología Educativa: un punto de vista cognoscitivo. México: Trillas, 1983

BRASIL. Comitê Nacional de Educação em Direitos Humanos. Plano Nacional de Educação em Direitos Humanos. Brasília: Secretaria Especial dos Direitos Humanos, MEC e Ministério da Justiça, UNESCO, 2006.

Brasil. Secretaria de Educação Fundamental. Parâmetros curriculares nacionais: introdução aos parâmetros curriculares nacionais / Secretaria de Educação Fundamental. - Brasília: MEC/SEF, 1996.

DELORS, J. Educação: um tesouro a descobrir. Relatório UNESCO da Comissão Internacional sobre Educação para o século XXI. São Paulo. Cortez Editora; Brasília. MEC/UNESCO. 2001, 288p.

FREIRE, P. Política e educação. São Paulo: Cortez, 1997. - Pedagogia da Autonomia: saberes necessários à prática educativa. 33 ed. São Paulo: Paz e terra, 1997.

KRASILCHIK, M. Educação Ambiental na escola brasileira passado, presente e futuro. Ciência e Cultura, São Paulo, v. 38, n. 12, p. 1958-1961, 1986.

VILHENA, A., POLITI, E. Reduzindo, reutilizando, reciclando: a indústria eficiente, São Paulo: CEMPRE, 2000.

PIAGET, J. Epistemologia Genética. Tradução de Os Pensadores. São Paulo: Abril Cultural, 1983.

\section{Sites utilizados}

Portal.inep.gov.br/...educacao-ambiental/-/asset.../sites-educacaoambient..

https://pt.wikipedia.org/wiki/Aterro_sanitario 